\title{
Loss of Retinoschisin (RS1) Cell Surface Protein in Maturing Mouse Rod Photoreceptors Elevates the Luminance Threshold for Light-Driven Translocation of Transducin But Not Arrestin
}

\author{
Lucia Ziccardi, ${ }^{1}$ Camasamudram Vijayasarathy, ${ }^{2}$ Ronald A. Bush, ${ }^{2}$ and Paul A. Sieving ${ }^{2,3}$ \\ ${ }^{1}$ G. B. Bietti Foundation, Istituto di Ricovero e Cura a Carattere Scientifico (IRCCS), 00198 Rome, Italy, ${ }^{2}$ Section on Translational Research for Retinal and \\ Macular Degeneration, National Institute on Deafness and Other Communication Disorders, and ${ }^{3}$ National Eye Institute, National Institutes of Health, \\ Bethesda, Maryland 20892
}

Loss of retinoschisin (RS1) in Rs1 knock-out (Rs1-K0) retina produces a post-photoreceptor phenotype similar to X-linked retinoschisis in young males. However, $R s 1$ is expressed strongly in photoreceptors, and $R s 1-\mathrm{K} 0$ mice have early reduction in the electroretinogram a-wave. We examined light-activated transducin and arrestin translocation in young Rs1-KO mice as a marker for functional abnormalities in maturing rod photoreceptors. We found a progressive reduction in luminance threshold for transducin translocation in wild-type (WT) retinas between postnatal days P18 and P60. At P21, the threshold in Rs1-K0 retinas was 10-fold higher than WT, but it decreased to $<2.5$-fold higher by P60. Light-activated arrestin translocation and re-translocation of transducin in the dark were not affected. Rs1-KO rod outer segment (ROS) length was significantly shorter than WT at P21 but was comparable with WT at P60. These findings suggested a delay in the structural and functional maturation of Rs1-KO ROS. Consistent with this, transcription factors CRX and NRL, which are fundamental to maturation of rod protein expression, were reduced in ROS of Rs1-K0 mice at P21 but not at P60. Expression of transducin was 15-30\% lower in P21 Rs1-KO ROS and transducin GTPase hydrolysis was nearly twofold faster, reflecting a 1.7- to 2.5-fold increase in RGS9 (regulator of G-protein signaling) level. Transduction protein expression and activity levels were similar to WT at P60. Transducin translocation threshold elevation indicates photoreceptor functional abnormalities in young Rs1-K0 mice. Rapid reduction in threshold coupled with age-related changes in transduction protein levels and transcription factor expression are consistent with delayed maturation of $R s 1-\mathrm{KO}$ photoreceptors.

\section{Introduction}

Retinoschisin protein (RS1; Swiss-Prot accession number NP_000321.1) is expressed in all neurons except horizontal cells in the developing and adult mouse retina but most prominently in photoreceptor inner segments (IS), in which it is localized to the external plasma membrane (Takada et al., 2004). The role of RS1 in photoreceptor function has not been identified, but mutations in the retinoschisin gene cause a retinal dystrophy in young males known as X-linked retinoschisis (Sauer et al., 1997) characterized by delamination of internal retinal structure and consequent reduction in retinal signaling (Manschot, 1972) as measured by the reduced b-wave of the electroretinogram (ERG).

Received April 19, 2012; revised July 14, 2012; accepted July 24, 2012.

Author contributions: L.Z., C.V., R.A.B., and P.A.S. designed research; L.Z., C.V., R.A.B., and P.A.S. performed research; L.Z., C.V., R.A.B., and P.A.S. analyzed data; L.Z., C.V., R.A.B., and P.A.S. wrote the paper.

This work was supported by the Intramural Research Program of the National Institutes of Health, National Institute on Deafness and Other Communication Disorders, and the National Eye Institute. We thank Robert N. Fariss and Maria M. Campos for technical assistance with confocal imaging and immunohistochemistry and Maria C. Santos for assistance with animal breeding and experiments.

Correspondence should be addressed to Paul A. Sieving, National Eye Institute, National Institutes of Health, 31 Center Drive, Room 6A03, Bethesda, MD 20892. E-mail: paulsieving@nei.nih.gov.

DOI:10.1523/JNEUROSCI.1913-12.2012

Copyright $\odot 2012$ the authors $\quad 0270-6474 / 12 / 3213010-12 \$ 15.00 / 0$
The features of this disease and the presence of a discoidin domain in retinoschisin have led to the generally accepted notion that it functions as an adhesion protein to maintain retinal architecture (for review, see Molday et al., 2012). The retinoschisin knock-out (Rs1-KO) mouse has a similar phenotype but also has a reduced photoreceptor a-wave and reduced rod outer segment (ROS) length as early as 1 month, and photoreceptor loss is apparent by 4 months (Kjellstrom et al., 2007).

Light-activated movement of phototransduction proteins between photoreceptor compartments involves major aspects of rod function, including photon capture, phototransduction, and light adaptation. In the dark, the heterotrimer transducin $(\mathrm{G} \alpha \beta \gamma)$ resides in the ROS, and arrestin localizes in the inner segment (IS). When the light intensity reaches a critical threshold at which the rate of activation of transducin $\alpha\left(\mathrm{G} \alpha_{\mathrm{t} 1}\right)$ exceeds the rate of inactivation by GTP hydrolysis (Kerov et al., 2005; Lobanova et al., 2007), G $\alpha_{\mathrm{t} 1}$ moves from the ROS into the IS and the cell body. This movement helps to set the dynamics of rod sensitivity and adaptation (Sokolov et al., 2002; Mendez et al., 2003; Zhang et al., 2003; Calvert et al., 2006; Lobanova et al., 2007) and may afford protection from light stress (Burns and Arshavsky, 2005). In response to light, arrestin moves in recipro- 
cal manner from the IS to the ROS in which it quenches photoactivated rhodopsin $\left(R^{\star}\right)$. The level of $R^{\star}$ (Nair et al., 2005) and the strength of the transduction signal (Strissel et al., 2006) have been proposed as stimuli for arrestin translocation into the ROS.

To address the role of RS1 in photoreceptor function at an early age, we investigated the effect of the loss of Rs1 expression on transducin and arrestin translocation light activation threshold between postnatal days P21 and P60. We found that P21 Rs1-KO mice have a much higher threshold than wild-type (WT) mice for transducin translocation, but it decreases rapidly with age and is more similar to WT at P60. Arrestin translocation threshold is not affected. This suggests the possibility of a delay in maturation of phototransduction processes involved in transducin translocation in Rs1-KO photoreceptors. Consistent with this, we found that photoreceptor transcription factors CRX and NRL are reduced in Rs1-KO mice at $\mathrm{P} 21$ but not $\mathrm{P} 60$. In addition, a large proportion of the translocation threshold increase in Rs1-KO mice at P21 could be explained by a reduction in transducin levels and an increase in GTPase activity.

\section{Materials and Methods}

Animals. This research was conducted in accordance with the Association for Research in Vision and Ophthalmology Statement on the Use of Animals in Ophthalmic and Vision Research. Rs1-KO mice and littermate control WT male mice were studied at P18, P21, P28, P35, and P60, in which P1 corresponds to the day of birth for purposes of this paper. Animals were born and reared in our laboratory derived from the founders originally described by Zeng et al. (2004). The Rs1-KO mice have been backcrossed for at least 20 generations onto C57BL/6J background and were reared on a $12 \mathrm{~h}$ light/dark cycle of 20 lux. Food and water were available ad libitum. Animals were weaned at 3 weeks of age. All Rs1-KO mice in the study were genotyped from tail DNA to verify that they carried the Rs1-KO construct.

Light-activated transducin and arrestin translocation by immunohistochemistry. Dark-adapted WT and Rs1-KO mice were anesthetized with intraperitoneal administration of ketamine $(80 \mathrm{mg} / \mathrm{kg})$ and xylazine $(4$ $\mathrm{mg} / \mathrm{kg}$ ). After pupil dilation with topical $0.5 \%$ tropicamide and $0.5 \%$ phenylephrine $\mathrm{HCl}$, they were placed on a heating pad $\left(\right.$ at $\left.37^{\circ} \mathrm{C}\right)$ facing a full-field illumination (Ganzfeld bowl) and exposed to 1, 2, 6, 12, 18, 30, $60,120,180$, or 300 scotopic candela per square meter $\left(\mathrm{sc} . \mathrm{cd} / \mathrm{m}^{2}\right)$ of white light for $1 \mathrm{~h}$ unless indicated otherwise.

For immunohistochemical analysis of transducin and arrestin translocation, mice were killed immediately after light exposure with $\mathrm{CO}_{2}$, and the eyes were quickly removed and placed in $4 \%$ paraformaldehyde in 0.1 M phosphate buffer, $\mathrm{pH} 7.4$, at $4^{\circ} \mathrm{C}$ for $12 \mathrm{~h}$. The fixed eye tissues were rinsed in PBS and trimmed to prepare eyecups. Eyecups were embedded in $7 \%$ agarose/PBS, $\mathrm{pH} 7.4$, and $100-\mu \mathrm{m}$-thick retinal sections were cut by Vibratome (model VT1000S; Leica Microsystems).

Single-labeling experiments were performed by incubating the sections with one of the primary antibodies overnight at $4^{\circ} \mathrm{C}$ in a medium containing 5\% normal goat serum $(\mathrm{G}), 0.2 \%$ Triton $\mathrm{X}-100(\mathrm{~T})$, and $0.05 \%$ sodium azide (A) in PBS (GTA-PBS). The antibodies and the dilutions used were as follows: rabbit polyclonal antibody against transducin $\alpha\left(\mathrm{G} \alpha_{\mathrm{t} 1}\right.$; Santa Cruz Biotechnology) at 1:800; rabbit polyclonal antibody against arrestin (from Igal Gery, National Eye Institute at National Institutes of Health, Bethesda, MD) at 1:2000; and mouse monoclonal antibody against rhodopsin (RET-P1; Abcam) at 1:2500. The sections were washed with GTA-PBS and incubated with fluorescent conjugated secondary antibodies for $2 \mathrm{~h}$ in appropriate combinations: Alexa Fluor 488 or 568-conjugated goat anti-mouse or goat anti-rabbit IgG (Invitrogen). The typical dilutions were 1:1000. A fluorescent nuclear stain, 4',6-diamidino-2-phenylindole (DAPI) (1:5000; SigmaAldrich) was also used to visualize nuclei in retinal sections. The sections were wet mounted on glass slides with Fluorogel (EM Sciences) for analysis and visualized with a confocal microscope (TCS SP-2; Leica Microsystems). Digital images $(1024 \times 1024$ pixels, $375 \times 375 \mu \mathrm{m})$ were acquired and processed in Photoshop (Adobe Systems). All im- ages were taken under identical conditions of laser intensity, brightness, and contrast.

Maximum projections of 3-20 confocal $z$-series images taken at 1.3-2 $\mu \mathrm{m}$ steps through sections from the retinas of 66 mice (36 Rs1-KO and $30 \mathrm{WT}$ ) were analyzed to determine the threshold intensity for transducin translocation. Threshold was defined as the intensity at which outer plexiform layer (OPL) staining could be clearly seen across most of the retinal length in the image. These evaluations were confirmed by measurement of fluorescent intensity in images from the retinas of 52 P21 and P60 WT and Rs1-KO mice using NIH Image J software. The program was used to construct vertical plot profiles of $\mathrm{G} \alpha_{\mathrm{t} 1}$ antibody and DAPI (when present) stain intensity $(0-255$ scale) from ROS tips to the inner nuclear layer (INL). DAPI and $\mathrm{G} \alpha_{\mathrm{t} 1}$ stain intensity was averaged over at least $100 \mu \mathrm{m}$ of retinal length in the same location but in separate images of each section (see Fig. $3 A$ ). Plot profiles were replotted for analysis in GraphPad Prism 6.0 for Windows (GraphPad Software). Image scanning and plotting was done without knowledge of the identity of the samples being analyzed. The luminance threshold for transducin translocation was defined as the exposure intensity at which the peak fluorescent stain intensity in the OPL relative to the peak ROS intensity (OPL/ROS) was significantly greater than the average OPL/ROS intensity in retinas of the same age and genotype exposed to $2 \mathrm{sc} . \mathrm{cd} / \mathrm{m}^{2}$ or less. The position of the OPL was confirmed in most sections by the decline in the DAPI signal adjacent to the outer nuclear layer (ONL) (see Fig. 3A).

Retinal morphometry. ONL thickness and ROS length were determined from $100 \mu \mathrm{m}$ vibratome sections containing the central retina and optic nerve cut from agarose-embedded tissues processed as described above. For each genotype (Rs1-KO and WT) and for each age group (P21 and P60), eight sections were analyzed. Rhodopsin-labeled retinal sections were used to measure ROS length, and ONL thickness was measured in DAPI-stained sections. From each section, five values of ONL thickness and ROS length in five separate locations within $500 \mu \mathrm{m}$ on each side of the optic nerve were determined and averaged. The product (ROS length $\times$ ONL thickness), which reflects the total plasma membrane area of the ROS containing c-GMP-gated channels (Machida et al., 2000), was calculated using the averages from these eight retinal sections. The length of the entire retina was measured in these same sections and compared across age and genotype. Statistical analysis by age and genotype was done using the two-way ANOVA followed by Sidak's multiple comparison test using GraphPad Prism 6.0.

Isolation of ROS and single-turnover GTPase assay. To maintain the retina in fully dark-adapted state, all procedures were performed under infrared illumination using night-vision goggles. Retinas from darkadapted mice were collected on ice in $8 \%$ OptiPrep (Sigma) in Ringer's buffer, pH 7.4 [in mM: $130 \mathrm{NaCl}, 3.6 \mathrm{KCl}, 2.4 \mathrm{MgCl}_{2}, 1.2 \mathrm{CaCl}_{2}, 10$ HEPES with $\mathrm{KOH}$, and 0.02 EDTA plus Halt protease inhibitor cocktail (Thermo Fisher Scientific)]. The ROS from eight retinas were isolated by step gradient (10 and 18\% OptiPrep in Ringer's solution) centrifugation procedure (Tsang et al., 1998). ROS were lysed by hypotonic shock in $90 \mu \mathrm{l}$ of $\mathrm{H}_{2} \mathrm{O}$ for $10 \mathrm{~s}$ by vortexing and then resuspended in $100 \mu \mathrm{l}$ of GTPase assay buffer (in mM: 10 Tris, pH 7.8, $100 \mathrm{NaCl}, 8 \mathrm{MgCl}_{2}$, and 1 DTT, plus Halt protease inhibitor cocktail). Single turnover $\mathrm{G} \alpha_{\mathrm{t}}$ GTPase assays were performed in triplicate as described previously (Cowan et al., 2000). ROS suspension in the assay buffer was bleached using a $1 \mathrm{~ms}$ white photoflash (Vivitar 283; Vivitar) producing $\sim 1 \%$ bleach done on ice shortly before each reaction. The experiment was started by mixing bleached ROS $(14 \mu \mathrm{l})$ containing $4 \mu \mathrm{m}$ rhodopsin with $7 \mu \mathrm{l}$ of $0.04 \mu \mathrm{M}$ $\left[\gamma^{-}{ }^{32} \mathrm{P}\right] \mathrm{GTP}$, and, at predetermined times, $100 \mu \mathrm{l}$ of $6 \%$ perchloric acid was added to the mixture to quench the reaction. The time course of ${ }^{32} \mathrm{Pi}$ (Pi, inorganic phosphate) formation was determined by the activated charcoal assay. The blank sample was quenched by acid before the addition of GTP, and the total activity sample was incubated for $10 \mathrm{~min}$ to achieve complete hydrolysis of all added GTP. The rate constants of transducin GTPase activity were determined by exponential fits of the results. The results of a representative experiment from at least three similar experiments are shown.

Western blot. Retinas or outer segment fragments from dark-adapted mice were lysed in RIPA buffer, pH 7.4 (50 mm Tris-HCl, 1\% NP-40, $0.25 \%$ sodium deoxycholate, $150 \mathrm{~mm} \mathrm{NaCl}$, and $1 \mathrm{~mm}$ EGTA) supple- 
mented with Halt protease inhibitor cocktail. Total protein (Pierce BCA protein assay kit; Thermo Fisher Scientific) and the levels of rhodopsin in isolated retinas or ROS were determined as described below. Retinal lysates or ROS extracts containing varying amounts of rhodopsin were run on Criterion TGX Any kD gels (Bio-Rad) and blotted onto PVDF membranes by wet transfer. The membranes were blocked in blocking buffer (LI-COR Biosciences) and later incubated overnight with one of the indicated primary antibody diluted in PBS containing $0.05 \%$ Tween 20 (PBST), pH 7.5, at $4^{\circ} \mathrm{C}$. The antibodies used included the following: transducin $\alpha$ subunit $\left(\mathrm{G} \alpha_{\mathrm{t} 1}\right.$, rabbit polyclonal, 1:1000); transducin $\beta$ subunit $\left(\mathrm{G} \beta_{1}\right.$, rabbit polyclonal, 1:2000); transducin $\gamma$ subunit $\left(\mathrm{G} \gamma_{1}\right.$, rabbit polyclonal, 1:2000); phosphodiesterase $6 \gamma$ (PDE6 $\gamma$, rabbit polyclonal, 1:1000); CRX (rabbit polyclonal, 1:500); G-protein-coupled receptor kinase 1 (mouse monoclonal, 1:500); regulator of G-protein signaling 9 (RGS9, goat polyclonal, 1:400) (all from Santa Cruz Biotechnology); recoverin (rabbit polyclonal, 1:1000; Millipore); visual arrestin (rabbit polyclonal, 1:300; Sigma); phosphodiesterase $6 \alpha(\mathrm{PDE} 6 \alpha$, rabbit polyclonal, 1:500; Thermo Fisher Scientific); phosducin (sheep polyclonal, 1:2500; from Maxim Sokolov, Department of Ophthalmology, West Virginia University Eye Institute, Center for Neuroscience, Morgantown, WV); Otx1 + Otx2 (rabbit polyclonal, 1:1000; Abcam); and NRL (rabbit polyclonal, 1:2500; from Anand Swaroop, National Eye Institute, Bethesda, MD). After overnight incubation, the membranes were rinsed three times in PBST and incubated with one of the following appropriate IRDye-conjugated secondary antibodies: IRDye $800 \mathrm{CW}$ conjugated goat (polyclonal) anti-rabbit IgG or IRDye 800CW conjugated donkey (polyclonal) anti-goat IgG (from LI-COR Biosciences); or Alexa Fluor 680-conjugated goat anti-mouse IgG (Invitrogen). Blots were scanned on LI-COR Odyssey Infrared Imaging System (model 9120, LI-COR Biosciences) and analyzed using Odyssey software. The results shown are from one of three similar experiments that yielded similar results.

ERG recordings. Full-field scotopic ERGs were recorded from male Rs1-KO mice and male WT littermates at P21 and P60. Recordings were obtained only once from each mouse. Animals were dark adapted overnight and prepared under red dim light. Mice were anesthetized with intraperitoneal administration of ketamine $(80 \mathrm{mg} / \mathrm{kg})$ and xylazine $(4$ $\mathrm{mg} / \mathrm{kg}$ ). Pupils were dilated with topical $0.5 \%$ tropicamide and $0.5 \%$ phenylephrine $\mathrm{HCl}$. Body temperature was kept at $37^{\circ} \mathrm{C}$ with a heating pad. ERGs were recorded from both eyes simultaneously, but only left eye traces were used for analysis in the majority of the mice (32 of 36). After application of $1 \%$ tetracaine topical corneal anesthesia, gold wire recording loops were placed on the cornea with a drop of methylcellulose for corneal hydration. Gold wires on the sclera of each eye at the limbus were used as reference electrodes, and the ground electrode was attached to the tail. Scotopic ERG responses were elicited using single flashes from a xenon discharge source (Grass Photic Stimulator PS33 Plus; AstroMed) from -4.9 to $+0.6 \log \mathrm{cd} \cdot \mathrm{s} / \mathrm{m}^{2}$ in 0.5 - $\log$ steps. Responses were computer averaged with stimulus intervals of 3 to $180 \mathrm{~s}$ depending on stimulus intensity. Stimuli were presented in a Ganzfeld bowl that provided uniform full-field illumination, and stimulus intensity was attenuated with neutral density Wratten filters (Eastman Kodak). Responses were amplified at 2000 or 5000 gain and filtered using a $0.1 \mathrm{~Hz}$ to $1 \mathrm{kHz}$ bandpass.

Studies of the a-wave in mouse (Hetling and Pepperberg, 1999), cat and monkey (Robson and Frishman, 1998), and human (Hood and Birch, 1993) have shown that ERG b-wave and oscillatory potentials can begin to intrude on the rod contribution to the a-wave beginning at post-flash time of $10 \mathrm{~ms}$. Hence, we measured a-wave amplitude at $8 \mathrm{~ms}$ after flash onset to assess the photoreceptor contribution. Intensity series measurements were made on nine WT mice per age group, and on 11 and 7 Rs1-KO mice at P21 and P60, respectively.

Whole-retina rhodopsin content, regeneration rate, and photon capture. All mice were dark adapted for 16 h from 6:00 P.M. to 10:00 A.M., and all pre-bleach and post-bleach procedures were performed under infrared illumination. Mice were killed by $\mathrm{CO}_{2}$ asphyxiation, and retinas were removed by extrusion through a slit in the cornea and frozen at $-80^{\circ} \mathrm{C}$ (Winkler, 1972). This method of retinal isolation was originally developed for recording the rat whole retinal ERG in vitro, including the

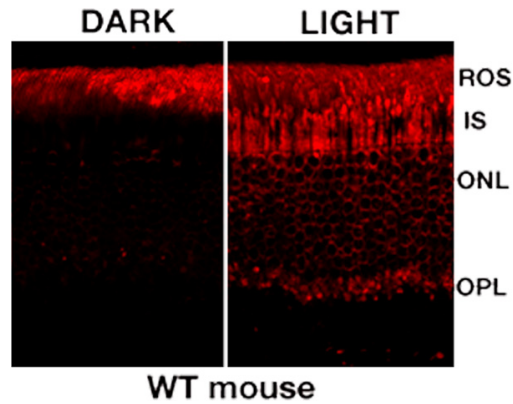

Figure 1. The light-dependent distribution of transducin $\alpha$-subunit $\left(\mathrm{G} \alpha_{\mathrm{t} 1}\right)$ in WT mouse retina. In normal mouse retina, $\mathrm{G} \alpha_{\mathrm{t} 1}$ distributes in the ROS layer in the dark and moves from the ROS to the IS, ONL, and OPL after light exposure (60 sc.cd// $\left.\mathrm{m}^{2}\right)$.

photoreceptor potential. It has been used successfully for biochemical assays, and especially rhodopsin quantification, in a variety of mouse and rat studies (Penn and Anderson, 1987; Sieving et al., 2001; Wenzel et al., 2001; Haruta et al., 2009; Skeie et al., 2011) and was shown to yield $>98 \%$ of the total retinal rhodopsin in a mouse model of retinal degeneration (Fulton et al., 1982). Rhodopsin from single retinas was extracted by disruption in $0.5 \mathrm{ml}$ of $1 \%$ emulphogene in $50 \mathrm{~mm}$ Tris-acetate buffer, $\mathrm{pH} 6.5$, incubation for $1 \mathrm{~h}$ at $4^{\circ} \mathrm{C}$, and centrifugation at $14,000 \times \mathrm{g}$ for 15 min. The supernatant was scanned from 700 to $400 \mathrm{~nm}$ using a Lambda 45 UV/Vis spectrophotometer (PerkinElmer Life and Analytical Sciences), bleached in 1200 lux for $10 \mathrm{~min}$, and then scanned again. Rhodopsin quantity per retina was calculated using the difference spectrum maximum absorbance, a $1 \mathrm{~cm}$ path length, and an extinction coefficient of $4.2 \times 10^{4} \mathrm{~mol}^{-1}$ (Shichi et al., 1969). Statistical analysis of darkadapted and steady-state bleach rhodopsin content by age and genotype was done by two-way ANOVA, followed by Sidak's multiple comparison test using GraphPad Prism 6.0 for Windows.

To compare the ability of Rs1-KO and WT retinas to activate transducin through photon capture by rhodopsin, we determined the rhodopsin regeneration rate in vivo in Rs1-KO and WT mice in the dark after exposure to steady illumination at an intensity and duration consistent with the transducin translocation experiments. The rate of formation of bleached rhodopsin is the rate of photon capture, and, under steady-state conditions, in which the rate of regeneration is the same as the rate of bleach, the regeneration rate can be used to calculate the rate of photon capture (Penn and Williams, 1986). First-order kinetics have been widely used to describe the regeneration rate of rhodopsin in rats (Tansley, 1931; Dowling, 1963; Penn and Williams, 1986) and mice (Wenzel et al., 2001), although other models have been proposed based on data from humans (Alpern and Krantz, 1981; Lamb and Pugh, 2004), cats (Ripps et al., 1981), and rodents (Lamb and Pugh, 2004). In addition, the kinetics of regeneration may be different under anesthesia (Perlman, 1978; Keller et al., 2001). We used the first-order kinetic model to allow comparison with previous mouse studies. In this model, the regeneration rate of rhodopsin is described by the first-order rate equation $r=-d[B] / d t=k_{r}$ $\times[B]$, where $r$ is the regeneration rate, $B$ is bleached rhodopsin, and $k_{r}$ is the regeneration rate constant. A plot of $\ln [B]$ is fit by a straight line with a slope equal to $-k_{r}$. In our experiments, the proportion of rhodopsin in the bleached state at time $(t)$ in the dark after exposure, $\left.\left(R_{0}-R_{t}\right) / R_{0}\right)$, where $R_{0}$ is the average dark-adapted rhodopsin level for the genotype and age of mice being tested, and $R_{t}$ is the average rhodopsin level measured at time $(t)$, was substituted for $[B]$, and $k_{r}$ was calculated as the slope of the linear regression fit to the values of $\ln \left(\left(R_{0}-R_{t}\right) / R_{0}\right)$ plotted against time in the dark (Penn and Williams, 1986).

For light exposure, unanesthetized mice were individually housed in clear plastic cages inside a well-ventilated light-tight box and exposed to diffuse white light for $1 \mathrm{~h}$ at $60 \mathrm{sc} . \mathrm{cd} / \mathrm{m}^{2}\left(45-70 \mathrm{sc} . \mathrm{cd} / \mathrm{m}^{2}\right.$ in the horizontal direction) provided by cool white fluorescent bulbs. One hour is sufficient time to reach a steady-state level of rhodopsin, because it was shown previously that the level of bleach in B6/129S(N2) mice exposed to 5,000 lux did not change between $10 \mathrm{~min}$ and 1 hour exposure (Wenzel et al., 2001). After exposure, mice were killed by $\mathrm{CO}_{2}$ at various times in the 

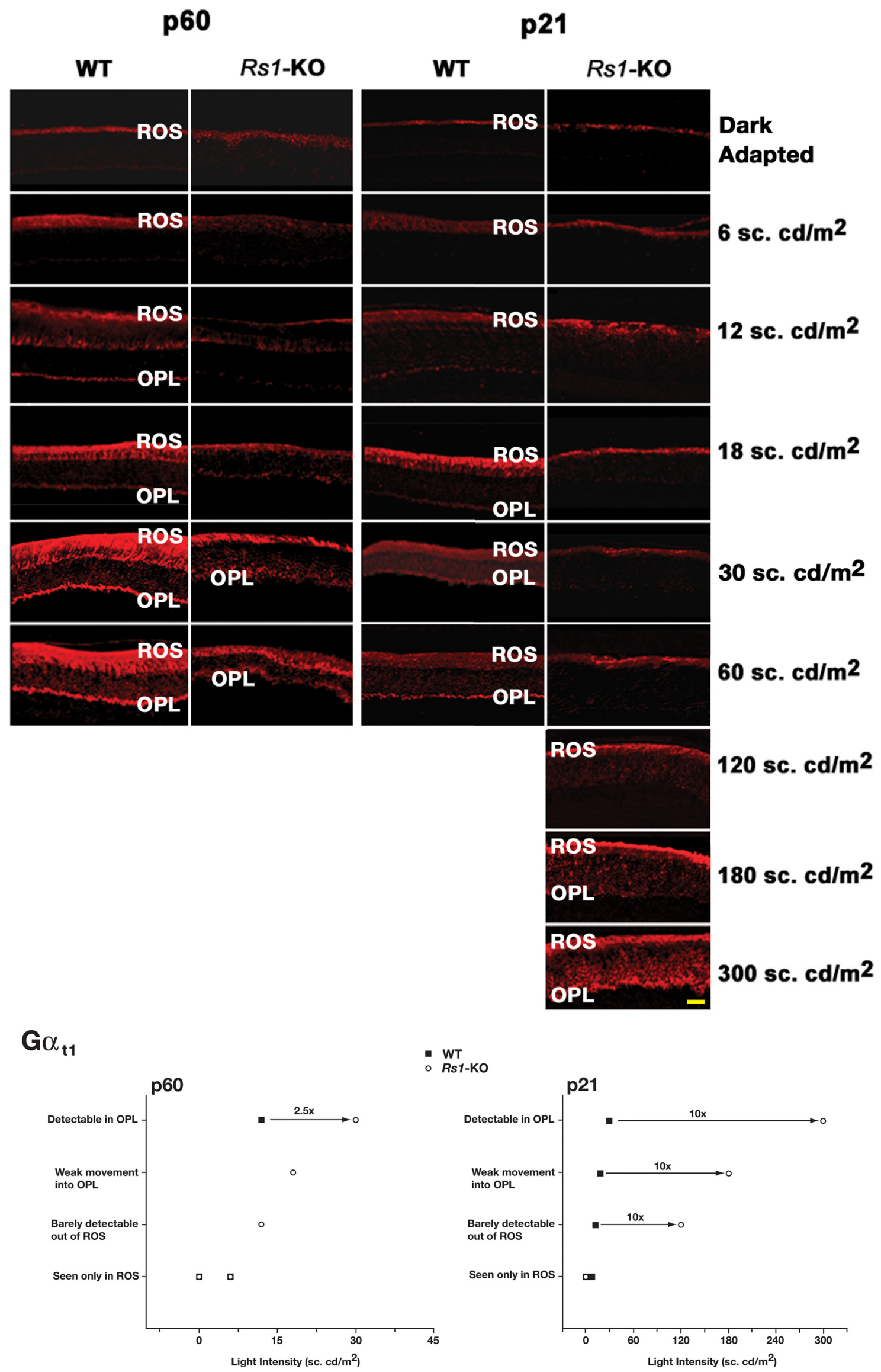

- WT

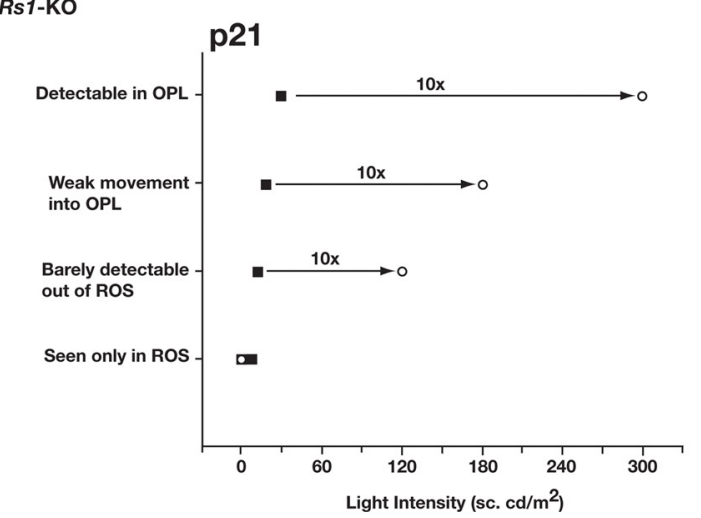

Figure 2. Light-intensity-dependent transducin translocation in WT and Rs1-K0 mice at P21 and P60. Animals were either dark adapted or exposed to $1 \mathrm{~h}$ of light of different intensities (indicated on the right). Comparison of $\mathrm{G} \alpha_{\mathrm{t} 1}$ distribution in WT and Rs1-K0 mice retinas shows that, in P21 and P60 WT retinas, $\mathrm{G} \alpha_{\mathrm{t} 1}$ translocates from R0S and distributes (Figure legend continues.) 
dark, and their retinas removed for rhodopsin measurement. For time 0 (steady-state bleach level), retinas were removed in the dark and frozen within 3 min after the lights were turned off. Rhodopsin in these samples was measured as described above for dark-adapted samples, and plotting and statistical comparison of rate plots was done using GraphPad Prism 6.0 for Windows.

\section{Results}

\section{Light-driven transducin translocation}

After extended dark adaptation, $\mathrm{G} \alpha_{\mathrm{t} 1}$ immunoreactivity was restricted to the ROS of both WT and Rs1-KO retinas. One hour of exposure to $60 \mathrm{sc} . \mathrm{cd} / \mathrm{m}^{2}$ triggered transducin translocation from ROS to the IS, ONL, and OPL in WT retina (Fig. 1). The transducin translocation threshold for P60 WT mice was $12 \mathrm{sc} . \mathrm{cd} / \mathrm{m}^{2}$ for complete distribution of $\mathrm{G} \alpha_{\mathrm{t} 1}$ into the IS and the OPL (Fig. 2), consistent with the previously reported value of $10 \mathrm{sc} . \mathrm{cd} / \mathrm{m}^{2}$ in adult C57BL/6 mice (Lobanova et al., 2007). The average OPL/ ROS G $\alpha_{\mathrm{t} 1}$ stain intensity signal in mice exposed to $12 \mathrm{sc} . \mathrm{cd} / \mathrm{m}^{2}$ was significantly greater than threshold ( $p<0.001, n=3$; Fig. $3 B, C)$. P21 WT retinas required higher light intensity: 12 $\mathrm{sc} . \mathrm{cd} / \mathrm{m}^{2}$ caused no transducin translocation, weak staining of transducin was observed in the OPL at $18 \mathrm{sc} . \mathrm{cd} / \mathrm{m}^{2}$, and staining was observed uniformly across the OPL at $30 \mathrm{sc} . \mathrm{cd} / \mathrm{m}^{2}$ (Fig. 2). The OPL/ROS $\mathrm{G} \alpha_{\mathrm{t} 1}$ stain intensity was significantly above threshold in WT retinas exposed to $18 \mathrm{sc} . \mathrm{cd} / \mathrm{m}^{2}(p<0.05, n=2)$ but not in those exposed to $12 \mathrm{sc} . \mathrm{cd} / \mathrm{m}^{2}$ ( $n=3$; Fig. $\left.3 \mathrm{~B}, C\right)$. Threshold was even higher at P18, because $30 \mathrm{sc} . \mathrm{cd} / \mathrm{m}^{2}$ was required to produce detectable staining in the OPL (data not shown) of WT mice.

Rs1-KO mice required higher light intensity for transducin translocation than age-matched WT mice at both P60 and P21; substantial movement from ROS into the OPL of Rs1-KO retinas at P60 occurred at $30 \mathrm{sc} . \mathrm{cd} / \mathrm{m}^{2}$. In stain intensity plot profiles, however, the average $\mathrm{G} \alpha_{\mathrm{t} 1}$ signal was significantly greater than threshold at $12 \mathrm{sc} . \mathrm{cd} / \mathrm{m}^{2}(p<0.01, n=3)$ and $18 \mathrm{sc} . \mathrm{cd} / \mathrm{m}^{2}(p<$ $0.01, n=4)$, although the amplitude of the signal was much lower than WT. At P28 and P35, however, translocation was incomplete at $60 \mathrm{sc} . \mathrm{cd} / \mathrm{m}^{2}$, with a reduced level of $\mathrm{G} \alpha_{\mathrm{t} 1}$ staining in an irregular pattern extending into the IS (data not shown). The movement of transducin from ROS into IS was barely detectable at $120 \mathrm{sc} . \mathrm{cd} / \mathrm{m}^{2}$ in P21 Rs1-KO mice, but some transducin staining was clearly seen at $180 \mathrm{sc} . \mathrm{cd} / \mathrm{m}^{2}$ and was detectable by image scanning (Fig. 3B). However, the combined average signal intensity in retinas exposed to $120-180$ sc.cd.m ${ }^{2}(n=3)$ was not significantly above threshold (Fig. $3 C$ ). Unambiguous detection of transducin in the OPL occurred by $300 \mathrm{sc} . \mathrm{cd} / \mathrm{m}^{2}$ at P21 (Fig. 2), and the OPL/ROS intensity ratio was significantly greater than threshold ( $p<0.01, n=2)$ and similar to WT (Fig. 3C). Overall, transducin translocation in adult $\mathrm{P} 60$ Rs1-KO retinas required $<2.5$-fold higher light intensity compared with P60 WT retinas, but at P21, G $\alpha_{\mathrm{t} 1}$ movement into the OPL was seen in $R s 1-\mathrm{KO}$ retinas only at 10 -fold higher light intensity compared with P21 WT retinas. Image scanning for stain intensity showed similar results but with slightly lower thresholds for WT at P21 and for $R s 1-\mathrm{KO}$ at $\mathrm{P} 60$, so that the thresholds were $\geq 10$-fold different at

\section{$\leftarrow$}

(Figure legend continued.) into OPL at much lower light intensities compared with Rs 1-K0 retinas. Immunofluorescence of $\mathrm{G} \alpha_{\mathrm{t} 1}$ in $\mathrm{P} 21 \mathrm{Rs} 1-\mathrm{K} 0$ retinas shows persistent staining only in the ROS. Only exposure to very bright light $\left(180-300 \mathrm{sc} . \mathrm{cd} / \mathrm{m}^{2}\right)$ caused $\mathrm{G} \alpha_{\mathrm{t} 1}$ distribution into the OPL. The inset shows the light intensities at which movement of $\mathrm{G} \alpha_{\mathrm{t} 1}$ out of the ROS and into the OPL was detected in P21 and P60 Rs 1-K0 and WT mice. All slides were visualized using the same microscope settings. Scale bar, $20 \mu \mathrm{m}$.
P21 and $<2.5$-fold different at P60 (Fig. 3C). This was not merely a delay in the response, because exposing for $3 \mathrm{~h}$ to $60 \mathrm{sc} . \mathrm{cd} / \mathrm{m}^{2}$ also failed to cause transducin translocation in $\mathrm{P} 21$ Rs1-KO retinas (data not shown).

\section{Arrestin translocation in light and re-translocation of transducin and arrestin in the dark}

Unlike transducin, arrestin staining was not seen in the ROS in the dark in either WT or Rs1-KO (P21, Fig. 4; P60, data not shown). After exposure to $2 \mathrm{sc} . \mathrm{cd} / \mathrm{m}^{2}$ for $1 \mathrm{~h}$, arrestin moved into the ROS of both WT and Rs1-KO, although there were subtle differences in protein localization in the dark-adapted retinas and retinas exposed to $1 \mathrm{sc} . \mathrm{cd} / \mathrm{m}^{2}$ : arrestin was prominent in the ONL and IS of WT retinas, but arrestin immunolabeling of Rs1-KO retinas was mainly in the ONL and not in the IS. At $1 \mathrm{sc} . \mathrm{cd} / \mathrm{m}^{2}$, very sparse arrestin staining of the ROS was barely visible in WT after $1 \mathrm{~h}$ and not detectable at all in Rs1-KO. Thus, the threshold light intensity for arrestin translocation for both WT and Rs1-KO mice at $\mathrm{P} 21$ was between 1 and $2 \mathrm{sc} . \mathrm{cd} / \mathrm{m}^{2}$. At $6 \mathrm{sc} . \mathrm{cd} / \mathrm{m}^{2}$, arrestin labeling was totally confined to the ROS in both lines. The migration to the ROS in light quenches $R^{\star}$ (Burns and Arshavsky, 2005), ultimately serving as a biochemical feedback to limit lightdriven rhodopsin activity and transduction.

The extinction of light activates the dark recovery phase that leads to the re-translocation of arrestin and transducin back into their respective compartments: transducin moves from the IS to the ROS, whereas arrestin re-translocates from the ROS to the IS (Sokolov et al., 2002). Because transducin in P21 Rs1-KO retinas translocated at a higher light intensity (300 sc.cd/m ${ }^{2}$ ) than P21 WT retinas (Fig. 2), we verified that transducin would move back into ROS in the dark after exposure to this intensity. In WT and Rs1-KO mice kept in the dark for $4 \mathrm{~h}$, the majority of transducin had moved from the OPL, ONL, and IS to the ROS layer (Fig. $5 A, B$ ). Re-translocation of arrestin in the dark from ROS to IS also occurred normally in $\mathrm{P} 21 \mathrm{WT}$ and Rs1-KO retinas after preexposure to $6 \mathrm{sc} . \mathrm{cd} / \mathrm{m}^{2}$ (Fig. 5C,D). These results demonstrate that the loss of RS1 protein did not impair the axial diffusion of transducin and arrestin between the photoreceptor compartments.

\section{Photoreceptor morphology and rhodopsin content}

Transducin translocation threshold in WT retinas showed a gradual reduction between $\mathrm{P} 18$ and $\mathrm{P} 60$, and there was a large elevation in threshold in P21 Rs1-KO mice, followed by rapid decline to near WT levels by P60. This suggested a delay in maturation of photoreceptor function, and we wondered whether there was a similar delay in maturation of photoreceptor morphology. Our previous study indicated shorter ROS compared with WT at 4 weeks, increasing to WT length by 4 months of age (Kjellstrom et al., 2007). In the P21 Rs1-KO retina, ONL thickness was $76 \%$ of WT at P21 $(p<0.0001)$ and $82 \%$ of WT at P60 $(p<0.05)$. Rs1-KO ROS length was $68 \%$ of WT at P21 $(p<$ 0.01 ) but was not significantly different from WT at P60 (Fig. 6). The ROS length in Rs1-KO increased significantly by $53 \%$ between P21 and P60 ( $p<0.05)$. WT ROS length increased 28\%, but the increase was not significant. Neither age nor genotype had a significant effect on length of the retina in sections from P21 and P60 mice ( $n=4-8$ per group).

Whole retina rhodopsin levels were significantly lower in P21 $R s 1-\mathrm{KO}$ than in $\mathrm{P} 21 \mathrm{WT}$ retinas $(p<0.0001 ;$ Table 1$)$. They increased $70 \%$ by $\mathrm{P} 60$ in $R s 1-\mathrm{KO}(p<0.0001)$ and $51 \%$ in WT $(p<0.0001)$. Although rhodopsin levels were still lower than WT at P60 $(p<0.0001)$, like ROS length, the increase between P21 
A

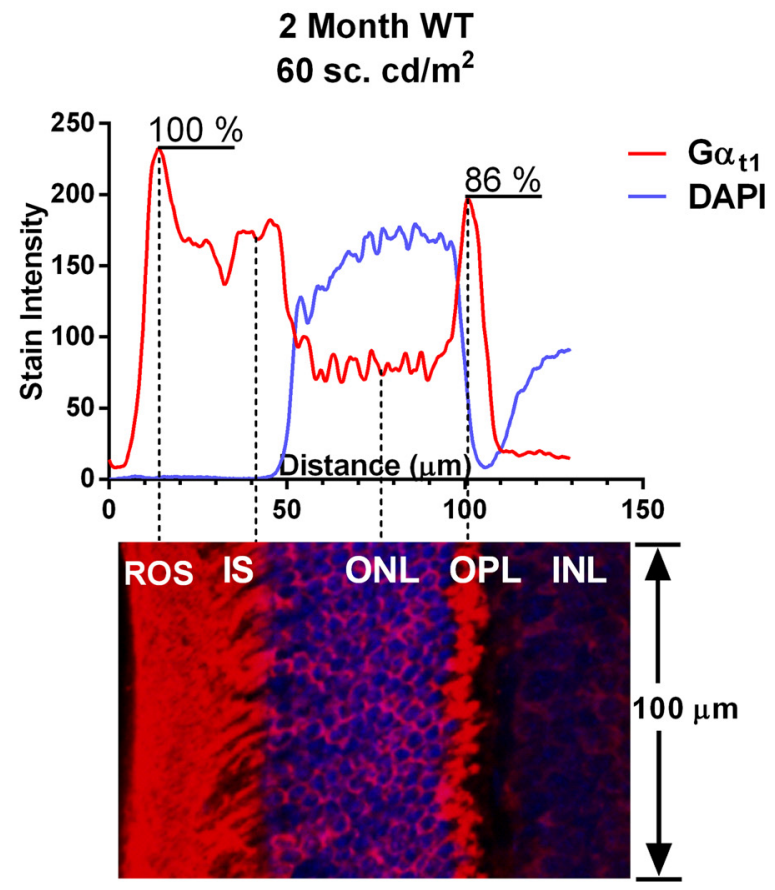

B

P21

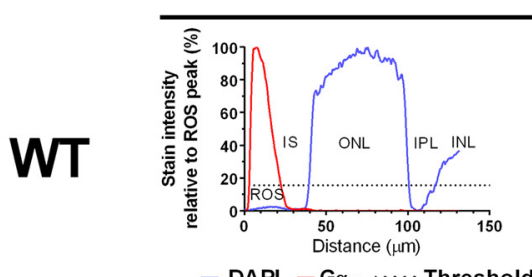

- DAPI $-G \alpha_{t 1} \cdots$ Threshold

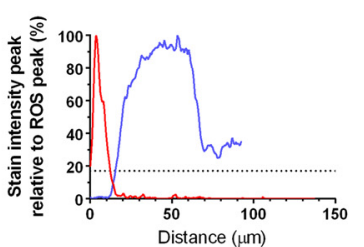

$\leq 2 \mathrm{sc} . \mathrm{cd} / \mathrm{m}^{2}$

Rs1-KO
C

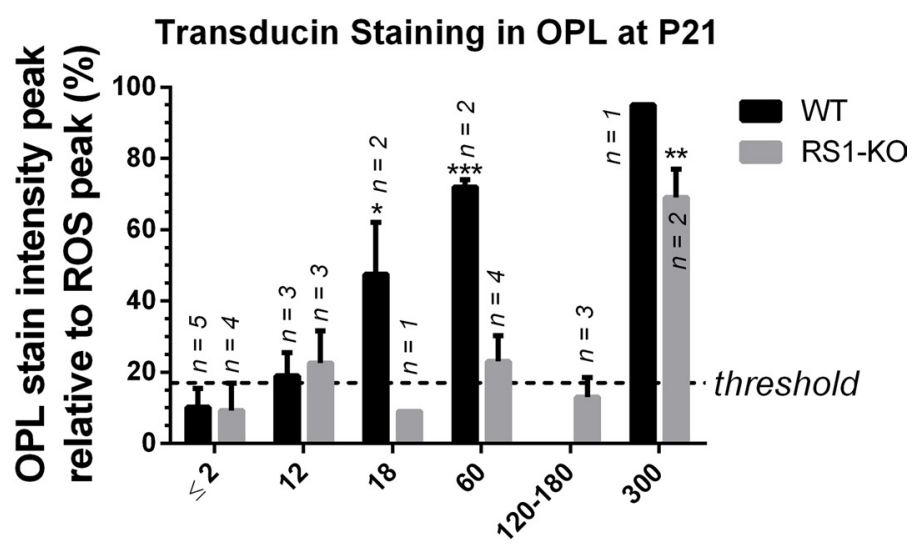

Light exposure (sc. $\mathrm{cd} / \mathrm{m}^{2}$ )

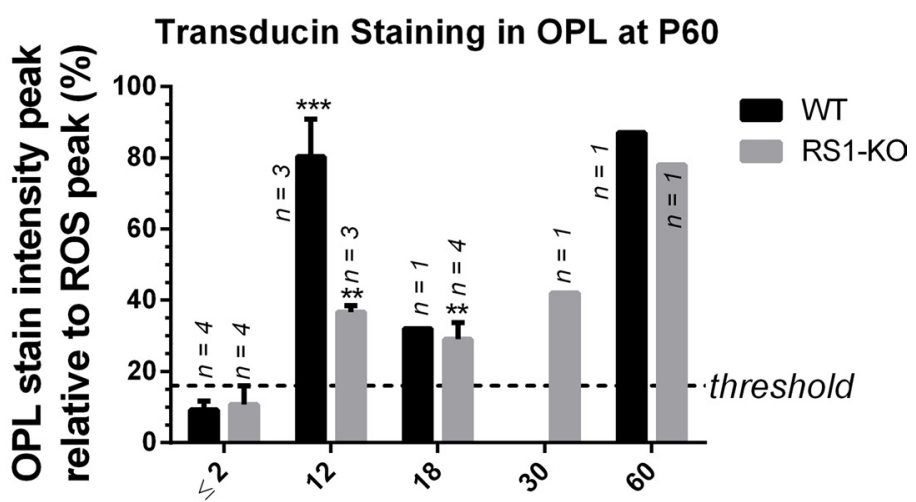

Light exposure (sc. cd/ $\mathrm{m}^{2}$ )

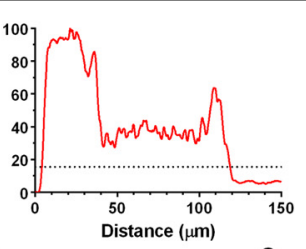

18 sc. $\mathrm{cd} / \mathrm{m}^{2}$

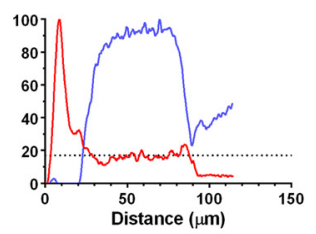

$180 \mathrm{sc} . \mathrm{cd} / \mathrm{m}^{2}$

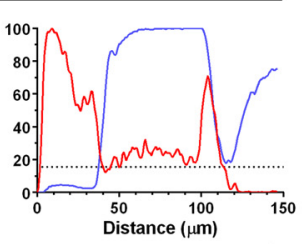

$60 \mathrm{sc} . \mathrm{cd} / \mathrm{m}^{2}$

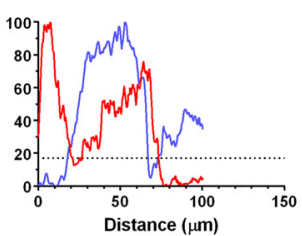

300 sc. $\mathrm{cd} / \mathrm{m}^{2}$

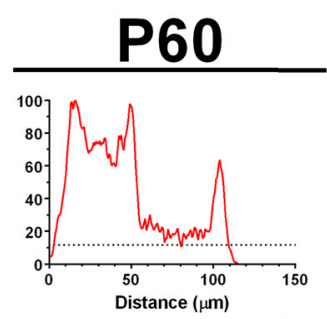

$12 \mathrm{sc} . \mathrm{cd} / \mathrm{m}^{2}$

Figure 3. Quantification of transducin translocation by measurement of $\mathrm{G} \alpha_{\mathrm{t} 1}$ staining intensity. $A$, Plot profiles of stain intensity in retinal sections from the ROS tips to the INL in confocal images. Values are the DAPI (blue) and $\mathrm{G} \alpha_{\mathrm{t} 1}$ (red) stain intensity on a scale of $0-255$ averaged over at least $100 \mu \mathrm{m}$ of retinal length. DAPI and $\mathrm{G} \alpha_{\mathrm{t} 1}$ channels were measured separately, and the merged image is shown below the graph. $\boldsymbol{B}$, Examples of plot profiles from WT and $R s 1-K 0$ mice replotted relative to the maximum ROS intensity in each section for comparison of OPL peak values. The threshold for transducin translocation (dashed line) was the combined average value of the OPL peak in retinas exposed to 0, 1, and $2 \mathrm{sc}$.cd/m ${ }^{2}$. The $0 \mathrm{PL} \mathrm{peak} \mathrm{is} \mathrm{clearly} \mathrm{above} \mathrm{threshold} \mathrm{in} \mathrm{P21} \mathrm{WT}$ at 18 and $60 \mathrm{sc.cd} / \mathrm{m}^{2}$, but $300 \mathrm{sc} . \mathrm{cd} / \mathrm{m}^{2}$ was required in P21 Rs 1-K0 mice. At P60, 12 and $30 \mathrm{sc.cd} / \mathrm{m}^{2}$ is enough to elicit OPL peaks above threshold in WT and Rs $1-\mathrm{K} 0$ mice, respectively. C, The average \pm SE OPL peak stain intensity as a percentage of ROS peak stain intensity plotted for WT and Rs $1-K 0$ at P21 and P60 as a function of light exposure intensity. WT is significantly above threshold at $18 \mathrm{sc} . c \mathrm{~d} / \mathrm{m}^{2}$ in P21 mice, but among Rs1-K0 mice, only those exposed to $300 \mathrm{sc} . \mathrm{cd} / \mathrm{m}^{2}$ are significantly above threshold. Dashed line is $0 \mathrm{PL}$ threshold as in $\boldsymbol{B}$. Statistically, the $0 \mathrm{PL}$ stain intensity in P60 Rs 1-K0 mice exceeds threshold at the same intensity as WT, $12 \mathrm{sc} . \mathrm{cd} / \mathrm{m}^{2}$. ${ }^{*} p<0.05,{ }^{* *} p<0.01,{ }^{* * *} p<0.001$, unpaired $t$ test corrected for multiple comparisons using the Holm-Sidak method (GraphPad Prism 6.0 for Windows). 
and P60 tended to be greater in Rs1-KO than in WT. Changes in transducin translocation threshold, ROS length, and rhodopsin during this period suggest a delay in the maturation of Rs1-KO photoreceptors.

Although whole retinal rhodopsin levels in $\mathrm{P} 21 \mathrm{Rs} 1-\mathrm{KO}$ retinas were only $\sim 40 \%$ of WT, an estimate of rhodopsin density in ROS [whole retina rhodopsin/ (ROS length $\times$ ONL cell number)] indicated that it was $80 \%$ of WT and did not change substantially between P21 and P60 (Table 1).

Expression levels of photoreceptorspecific transcriptional factors in Rs1-KO retinas

In mice, functional maturation of rod photoreceptors continues during the postnatal period for 2-4 weeks after the final mitosis and is attributed to the consecutive waves of gene expression patterns of NRL, CRX, nR2E3, and Otx2 that eventually lead to structurally and functionally mature rod photoreceptors and continue to be expressed at high levels in the mature retina (Levine et al., 2000; Swaroop et al., 2010). Thus, we wondered whether differences in the time course of changes in transducin translocation threshold and ROS length reflect a delay in rod maturation controlled by transcription factors. In quantitative immunoblot analysis of retinal extracts from Rs1-KO and WT retinas, we observed that the expression of $\mathrm{Nrl}$ and CRX was downregulated by 50 and $25 \%$, respectively, in Rs1-KO retinas at P21, but their expressions levels were comparable with WT at P60 (Fig. 7). These observations demonstrate that the regulation of the rod-specific transcriptional network controlling the expression of transduction and other ROS proteins is altered during maturation in the retinas of Rs1-KO mice. We also assessed the expression of Otx2, a homeobox gene product essential not only for rod photoreceptor cell fate determination but also in the morphological and electrophysiological maturation of bipolar cells (Koike et al., 2007). We found that the expression of Otx2 was downregulated by $30 \%$ at $\mathrm{P} 21$ and $40 \%$ at P60 in Rs1-KO retinas (Fig. 7).

\section{Transduction protein expression and} GTPase activity

The alteration in transcription factor levels at P21 but not P60 in Rs1-KO mice support the idea that the time course of photoreceptor maturation is altered. Changes in protein expression related to the maturational delay in the rod-specific transcriptional network could alter processes involved in phototransduction and explain the effects on the transducin translocation
DARK
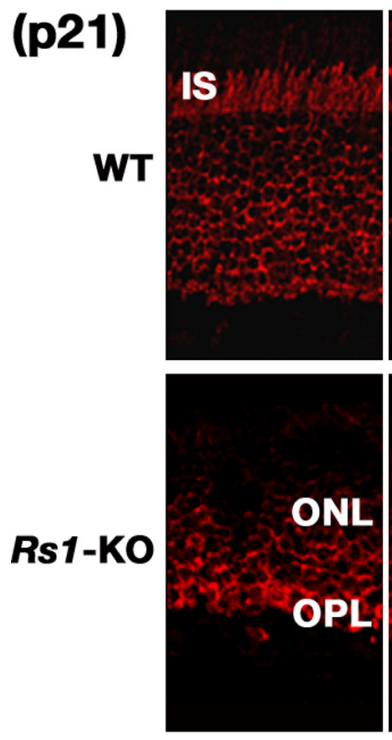

1 sc. $\mathrm{cd} / \mathrm{m}^{2}$
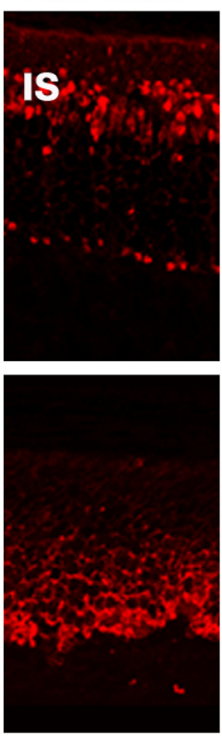

2 sc. $\mathrm{cd} / \mathrm{m}^{2}$
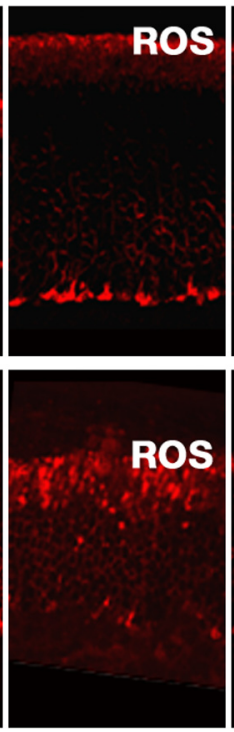

6 sc. $\mathrm{cd} / \mathrm{m}^{2}$

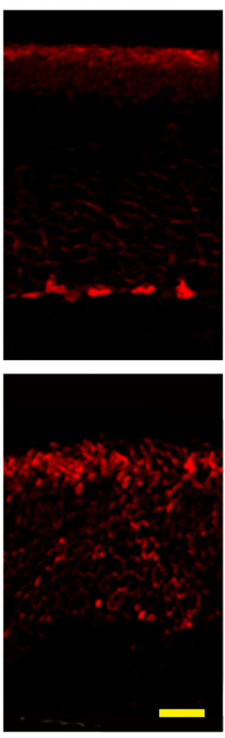

Figure 4. Arrestin movement in response to light in P21 WT and Rs1-K0 mice. In the dark, arrestin immunostaining was confined to the OPL, ONL, and IS in WT mice. After exposure to light intensity of $1 \mathrm{sc} . \mathrm{cd} / \mathrm{m}^{2}$ for $1 \mathrm{~h}$, arrestin was concentrated in the IS compartment, and very sparse staining was detected in the ROS. Light of $2 \mathrm{sc} . \mathrm{cd} / \mathrm{m}^{2}$ was able to mobilize arrestin from the IS to the ROS. In Rs1-K0 retina, the threshold light intensity for arrestin translocation was the same as WT retina. However, at light intensity below the threshold, arrestin redistribution in the inner retina was confined mainly in the ONL and OPL, and none was detected in the IS of Rs 1-KO mice. Scale bar, $15 \mu \mathrm{m}$.

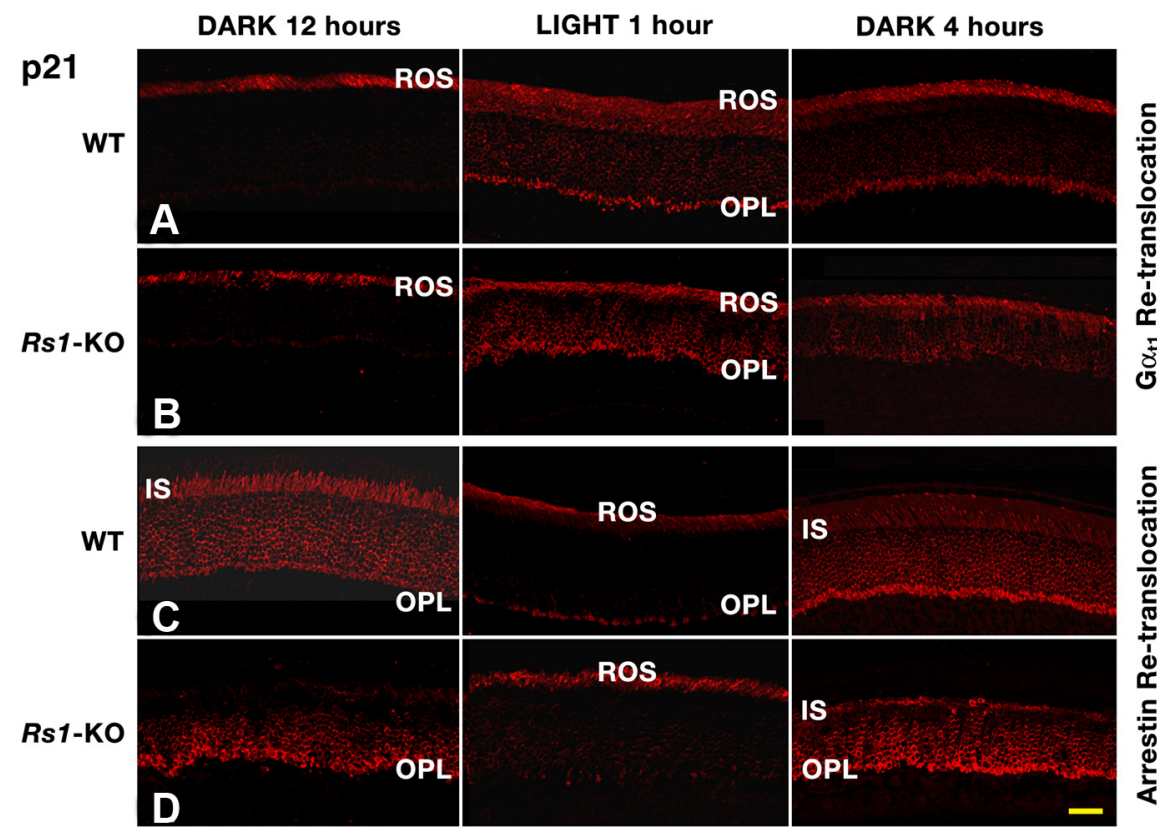

Figure 5. Re-translocation of $\mathrm{G} \alpha_{\mathrm{t} 1}$ (rows $\boldsymbol{A}$ and $\boldsymbol{B}$ ) and arrestin (rows $\boldsymbol{C}$ and $\boldsymbol{D}$ ) in P21 WT and Rs $1-\mathrm{K} 0$ mice retinas. Mice were dark adapted overnight ( $12 \mathrm{~h}$ ), exposed to light (for $1 \mathrm{~h}$ ), and then placed in the dark (for $4 \mathrm{~h}$ ). $\mathrm{G} \alpha_{\mathrm{t} 1}$ partially re-translocated into the ROS when mice were replaced in the dark for $4 \mathrm{~h}$ after exposure to $30 \mathrm{sc} . \mathrm{cd} / \mathrm{m}^{2}$ (WT, row $\boldsymbol{A}$ ) or $300 \mathrm{sc} . \mathrm{cd} / \mathrm{m}^{2}$ (Rs $1-\mathrm{KO}$, row $\boldsymbol{B}$ ) sufficient to cause translocation from the ROS into the OPL. Arrestin moved from the IS in dark to the ROS in the light $\left(6 \mathrm{sc} . \mathrm{cd} / \mathrm{m}^{2}\right)$ and then back into OPL in the dark in WT (row $\boldsymbol{C}$ ) and Rs 1-KO (row D) retinas. As in Figure 4, arrestin was not detected in the IS of Rs 1-K0 retina after $12 \mathrm{~h}$ dark adaptation. Scale bar, $22 \mu \mathrm{m}$.

threshold. The key factor determining transducin translocation threshold is the local concentration of activated $\mathrm{G} \alpha_{\mathrm{t} 1}$ generated by phototransduction after rhodopsin bleaching and its inactivation by GTP hydrolysis (Lobanova et al., 2007). We explored whether the quantity of activated transducin during rhodopsin bleaching is altered in $R s 1-\mathrm{KO}$ retinas as a result of the availability 

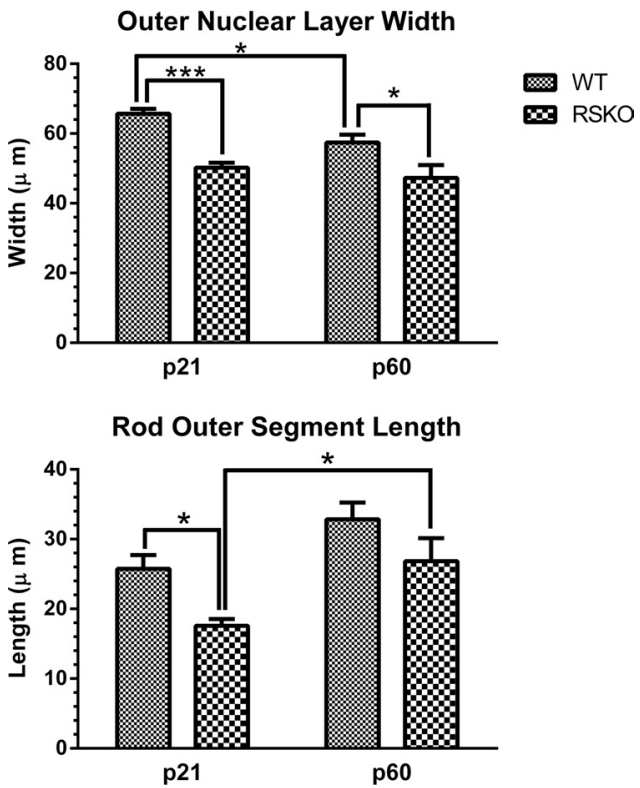

Figure 6. Age-related changes in photoreceptor morphology in WT and Rs1-K0 mice. Top, Compared with WT retinas, ONL width was thinner in Rs 1-K0 retina at both $\mathrm{P} 21(p<0.001)$ and P60 ( $p<0.05$ ). A significant $(p<0.05)$ thinning of the 0NL occurred in WT mice from P21 to $\mathrm{P} 60$, which was not seen in Rs 1-K0 retinas. Bottom, ROS in Rs 1-K0 were shorter compared with WT at P21 $(p<0.05)$, but their length increased significantly between $\mathrm{P} 21$ and $\mathrm{P} 60$ ( $p<$ 0.05 ) when $R s 1-K 0$ and WT were not significantly different. Error bars indicate mean \pm SE. $n=8$ mice for all histological measurements. ${ }^{*} p<0.05,{ }^{* * *} p<0.001$, two-way ANOVA and Sidak's multiple comparison test (GraphPad Prism 6.0 for Windows).

of transducin or the rate of inactivation by measuring the darkadapted levels of transducin and RGS9 and the rate of GTP hydrolysis after light exposure. Western blot analysis of retinal extracts normalized by rhodopsin ( $5 \mathrm{pmol}$ ) showed marginal differences in expression profiles of photo transduction proteins between WT and Rs1-KO mice retinas (results not shown). However, quantitative immunoblot analysis of extracts of purified outer segments revealed that transducin levels were consistently decreased relative to rhodopsin by $15-30 \%$ in Rs1-KO mice at P21 (Fig. 8A,C). Whereas PDE $\alpha$ and PDE $\gamma$ were slightly elevated relative to rhodopsin in Rs1-KO photoreceptors, RGS9, the GTPase-accelerating protein (GAP) for $\mathrm{G} \alpha_{\mathrm{t} 1}$, was elevated in Rs1-KO photoreceptors 1.7- to 2.5-fold above WT (Fig. 8B,D). These differences between WT and Rs1-KO retinas were not observed at P60 (data not shown). Consistent with this observation, we found that the rate of GTP hydrolysis by transducin in ROS of Rs1-KO mice was nearly twofold higher than that in WT retinas at $\mathrm{P} 21$ but indistinguishable from WT at P60 (Fig. 8E,F). The increased inactivation rate in Rs1-KO mice at P21 results in a shorter lifetime of activated transducin, which could shift the light intensity threshold for transducin translocation to higher intensity by reducing the amount of activated transducin present during exposure.

\section{The ERG and phototransduction}

To assess the in vivo light activation of transducin, we used the dark-adapted ERG a-wave, which is attributable to the entire rod transduction cascade leading to changes in the rod circulating dark current (Penn and Hagins, 1972; Baylor et al., 1984; Breton et al., 1994; Pugh et al., 1998). At a stimulus intensity of $+0.6 \log$ $\mathrm{cd} \cdot \mathrm{s} / \mathrm{m}^{2}$, the mean ERG a-wave maximum amplitude was reduced significantly in Rs1-KO mice at both ages compared with WT (P21, 63\%, $p<0.0001$; P60, 50\%, $p=0.0006$; unpaired $t$ test). However, when mean ERG a-wave amplitude values at $8 \mathrm{~ms}$ for Rs1-KO and WT mice at P21 and P60 were normalized by the corresponding mean dark-adapted whole retina rhodopsin content of each group, the V-log I response curves plotted for intensities up to $+0.6 \log \mathrm{cd} \cdot \mathrm{s} / \mathrm{m}^{2}$ showed nearly complete overlap (Fig. 9). In addition, the plot in Figure 9 (inset) shows that the maximum a-wave mean amplitude at $8 \mathrm{~ms}$ recorded from WT and Rs1-KO mice is linearly proportional to (ROS length $\times$ ONL width) as we described previously for a quite different model of photoreceptor degeneration, the $\mathrm{P} 23 \mathrm{H}$ rhodopsin rat (Machida et al., 2000). These findings confirm that the phototransduction process in Rs1-KO outer segments remains intact even with major morphological changes, implying that the elevation in transducin translocation threshold is not attributable to a deficiency in transducin activation.

\section{Rhodopsin bleaching, regeneration, and photon capture}

Transducin translocation threshold was monitored under conditions of constant illumination in which the activation of transducin depends on the continual bleach and recovery of rhodopsin. Although whole retinal rhodopsin levels in P21 Rs1-KO retinas were only $\sim 40 \%$ of WT, the local concentration of rhodopsin in ROS, calculated by normalizing by ROS length and an estimate of ONL cell number, was $80 \%$ of WT (Table 1). Calculation of the rate of rhodopsin turnover from the level of bleach and the regeneration rate constant measured at steady state under constant illumination indicated that photon capture was only slightly reduced in P21 Rs1-KO mice, nor was there a substantial change with age. This analysis was done under the steady-state illumination, as were the transducin translocation experiments, and indicate that Rs1-KO photoreceptors do not have a defect in rhodopsin kinetics that would lead to substantially reduced levels of activated transducin.

\section{Discussion}

\section{RS1 implicated in timely rod maturation}

The progressive decrease in luminance threshold for transducin translocation in WT mice from P18 to P21 to P60 indicates that changes in the sensitivity of transducin translocation are part of normal rod maturation. Three observations in this study suggest that the loss of Rs1 expression causes a delay in this maturation process: (1) there was an exaggerated, 10-fold, elevation of threshold in Rs1-KO mice at P21, which decreased to $<2.5$-fold above WT by P60; (2) there was a significant increase in ROS length in Rs1-KO mice after P21, when length normally has already reached adult levels in WT mice (LaVail, 1973) and rats (Fulton et al., 1995), going from $68 \%$ of WT $(p<0.05)$ to not significantly different from WT at P60; and (3) Rs1-KO mice had reduced levels of the transcription factors NRL and CRX at P21 but not P60. NRL and CRX regulate the expression of photoreceptor transduction proteins and are cooperatively involved in photoreceptor development but continue to have high expression levels in mature retina and help maintain rod homeostasis (Swaroop et al., 2010). This would suggest that delayed maturation of transducin translocation threshold in Rs1-KO mouse photoreceptors is a functional consequence of perturbations in the rod photoreceptor development specific gene regulatory network proteins and possibly directly mediated by delayed maturation in phototransduction processes.

\section{RS1 loss alters maturation-dependent photo transduction processes}

The delayed development of threshold sensitivity of transducin translocation in Rs1-KO mice was linked to phototransduction 


\begin{tabular}{|c|c|c|c|c|}
\hline & \multicolumn{2}{|l|}{$P 21$} & \multicolumn{2}{|l|}{ P60 } \\
\hline & WT & Rs1-K0 & WT & Rs1-K0 \\
\hline \multicolumn{5}{|l|}{ Molecules $\times 10^{14}$} \\
\hline \multicolumn{5}{|l|}{ Whole retina } \\
\hline Dark adapted $\left(R_{0}\right)$ & $2.35 \pm 0.17(n=6)$ & $0.98 \pm 0.16^{* *}(n=6)$ & $3.55 \pm 0.10(n=8)$ & $1.67 \pm 0.09^{* *}(n=8)$ \\
\hline Unbleached steady state $\left(R_{s s}\right)$ & $1.08 \pm 0.32(n=6)$ & $0.82 \pm 0.20(n=4)$ & $1.51 \pm 0.66(n=12)$ & $0.92 \pm 0.22^{*}(n=6)$ \\
\hline Bleached steady state $\left(B_{s \mathrm{ss}}=R_{0}-R_{\mathrm{ss}}\right)$ & 1.27 & 0.16 & 2.04 & 0.75 \\
\hline Regeneration rate constant $\left(k_{r}\right) / \mathrm{min}$ & $0.012 \pm 0.001(n=12)$ & $0.048 \pm 0.020^{*}(n=11)$ & $0.008 \pm 0.001(n=19)$ & $0.011 \pm 0.004(n=21)$ \\
\hline Photons/s/retina $\left(\left(k_{r} / 60\right) \times B_{s s}\right) \times 10^{10}$ & 2.54 & 1.28 & 2.72 & 1.38 \\
\hline \multicolumn{5}{|l|}{ Molecules $\times 10^{6} / \mu \mathrm{m}$ ROS } \\
\hline \multicolumn{5}{|l|}{ Whole retina/(ROS $\times 0 \mathrm{NL})$} \\
\hline Dark adapted $\left(R_{0}\right)$ & 1.25 & 1.00 & 1.69 & 1.18 \\
\hline Bleached steady state $\left(B_{s s}\right)$ & 0.67 & 0.15 & 0.97 & 0.53 \\
\hline Photons $/ s / \mu \mathrm{m} \operatorname{ROS}\left(\left(k_{r} / 60\right) \times \mathrm{B}_{\mathrm{ss}}\right) \times 10^{2}$ & 1.35 & 1.20 & 1.29 & 0.98 \\
\hline
\end{tabular}

Measured values $=$ mean $\pm \mathrm{SD} . R_{0}$, Rhodopsin in mice after $16 \mathrm{~h}$ dark adaptation; $R_{\mathrm{ss}}$, rhodopsin present after exposure of mice to $1 \mathrm{~h}$ of $60 \mathrm{sc} . \mathrm{cd} / \mathrm{m}^{2} ; B_{s s}$, rhodopsin bleached after exposure of mice to $1 \mathrm{~h}$ of $60 \mathrm{sc} . \mathrm{cd} / \mathrm{m}^{2}$, calculated from (average $R_{0}$ - individual mouse $\left.R_{s s}\right) ; k_{r}$, regeneration rate constant of rhodopsin in the dark [same in whole retina and whole retina/(ROS $\left.\times 0 \mathrm{NL}\right)$, calculated from the slope of the linear regression fit to $/ n\left(\left(R_{0}-R_{t}\right) / R_{0}\right)$, where $R_{t}$, $h$ odopsin at time ( $t$ minutes) in the dark after exposure to $1 \mathrm{~h}$ of $\left.60 \mathrm{sc.cd} / \mathrm{m}^{2}\right]$; ROS, average rod outer segment length (micrometers) from Figure 6; 0NL, estimated number of photoreceptor cells (average $0 \mathrm{NL}$ width/average $0 \mathrm{NL}$ width of $P 60 \mathrm{WT}$ ) ${ }^{*} 6.4 \times 10^{6}$ cells in adult WT C57BL/6 (Jeon et al., 1998); Whole retina/(ROS/ONL), whole retina rhodopsin values normalized by cell number and ROS length. ${ }^{*} p<0.05$; ${ }^{* *} p<0.0001$, significantly different from WT (two-way ANOVA, Bonferroni's multiple comparisons).

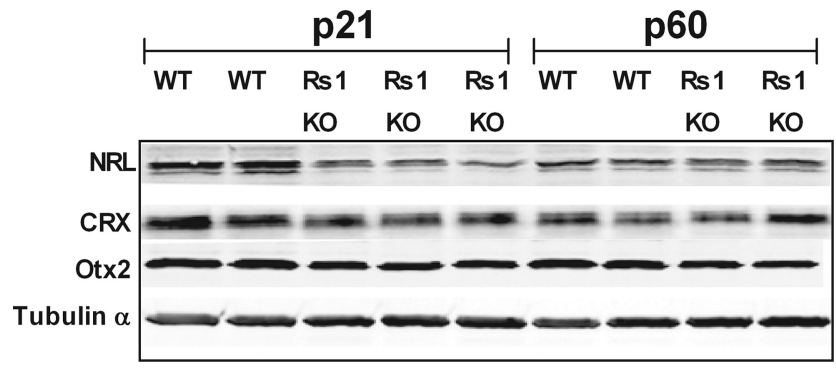

Figure 7. Expression levels of photoreceptor-specific transcription factors. Retinal protein extracts ( $\sim 10 \mu \mathrm{g}$ of total protein) from WT and $R s 7-K 0$ mice at ages P21 and P60 were Western blotted and probed for each of the transcription factor indicated on the left with specific antibodies, followed by anti-tubulin antibody. Expression levels were quantified using Odyssey software and normalized to $\alpha$-tubulin. At P21, all of these transcription factor levels were lower (by 25-50\%) in Rs1-K0 mice. However, at P60, both NRL and CRX levels were comparable with that collected from WT retinas. Replicate gels were run for each antibody tested.

by alterations in transducin and RGS9 levels and GTPase hydrolysis rate at $\mathrm{P} 21$, which were not seen at $\mathrm{P} 60$. We found a $15-30 \%$ reduction in transducin level relative to rhodopsin and a nearly twofold higher GTPase hydrolysis rate, which was consistent with the 1.7- to 2.5-fold higher RGS9 level. The critical factor affecting the threshold for transducin translocation is the level of $\mathrm{G} \alpha_{\mathrm{t} 1}$ produced by the activation/inactivation cycle during light exposure (Lobanova et al., 2007). Therefore, the decreased transducin and shorter lifetime of activated transducin in Rs1-KO mice at P21 could account for $\sim 60 \%$ of the tenfold elevation in transducin translocation threshold. Because these differences were found only at P21 and not at P60, we can conclude they had a major contribution to the shift in translocation threshold to higher light intensity in young Rs1-KO mice and its reduction with age. Thus, the elevated threshold in P21 Rs1-KO mice is a consequence of a delay in maturation of rod phototransduction processes and an indication of the consequences of the functional differences in phototransduction between immature and mature rods. From this perspective, our calculation of the degree of threshold elevation explained by GTPase activity and transducin levels has to be considered a very rough estimate, because the meaning of these changes in immature photoreceptors may be very different from more mature WT rods.

There may also have been modifications to elements of translocation other than those involved directly in phototransduction. Transducin translocation is thought to occur by diffusion in an energy-independent manner and not by active transport. We know from the ERG a-wave normalized by rhodopsin level that the phototransduction response, which involves diffusion controlled interactions with other transduction proteins within the disc (Calvert et al., 2001), was not impaired. However, factors that affect the axial diffusion and/or interdisc transfer of $\mathrm{G} \alpha_{\mathrm{t} 1}$ GTP (Kerov and Artemyev, 2011) would be more likely to play a role in transducin translocation. Also, although protein movement between inner and outer segment through the connecting cilium was apparently not restricted because re-translocation was not affected, movement within the proximal cell body and binding to targets in these compartments could be altered.

\section{Arrestin versus transducin translocation}

The pathology in the Rs1-KO retina alters the threshold for lightactivated transducin translocation out of the ROS but has no effect on arrestin translocation into the ROS in the light. To our knowledge, this is the first time that translocation of these two proteins has been investigated simultaneously in an animal model of photoreceptor pathology, and it shows that pathology can affect these mechanisms in a separable manner. This is consistent with independent pathways for at least the activation of transducin and arrestin translocation. Photoactivation of rhodopsin is requisite for both, but the level of activation required and downstream signaling mechanisms leading to activation, as well as binding partners that facilitate diffusion, are probably different (Slepak and Hurley, 2008; Elsaesser et al., 2010; Orisme et al., 2010; Satoh et al., 2010; Kerov and Artemyev, 2011). Transducin translocation is triggered at intensity levels beyond rod saturation and occurs by diffusion that depends on the concentration gradient of free $\mathrm{G} \alpha_{\mathrm{t} 1}$, which in turn is set by the rate of $\mathrm{G} \alpha_{\mathrm{t} 1}$ activation and inactivation. In comparison, very low levels of bleach near threshold (1.5-3.0\%), (Strissel et al., 2006) trigger a disproportionately large amount of arrestin translocation, leading to the idea that transduction-mediated signaling is required for triggering arrestin movement to ROS. This may include accessory signaling pathways, such as G-protein-linked phospholipase C (Orisme et al., 2010; Satoh et al., 2010). Extrapolating from our $54 \%$ rhodopsin bleach in WT mice exposed for $1 \mathrm{~h}$ at 60 sc.cd $/ \mathrm{m}^{2}$, the proportion of bleached rhodopsin at $2 \mathrm{sc} . \mathrm{cd} / \mathrm{m}^{2}$ would be $\sim 1.8 \%$, which agrees well with Strissel et al. (2006). However, others showed that arrestin translocation depends on the rate of accumulation of bleached rhodopsin that can bind arrestin (Nair et al., 2005; Slepak and Hurley, 2008) and propose 


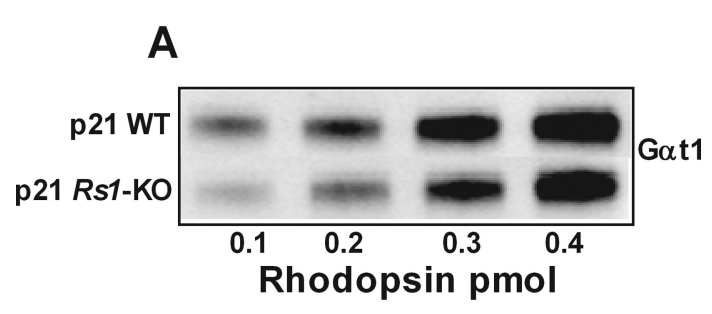

B

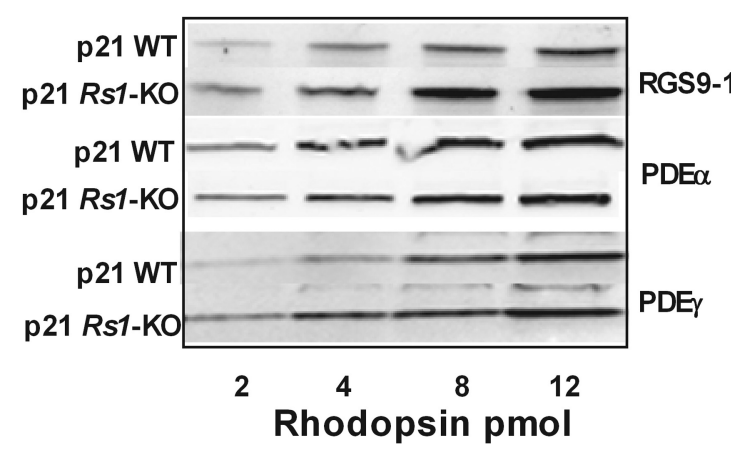

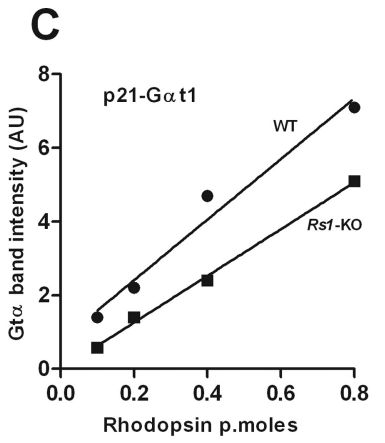

E

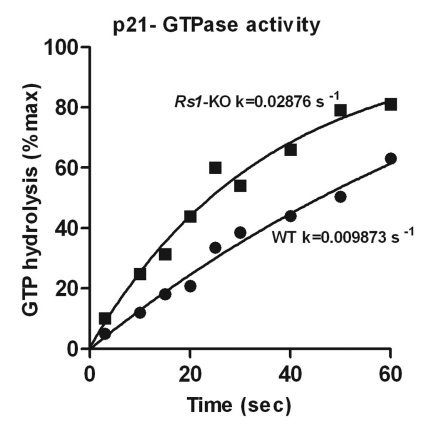

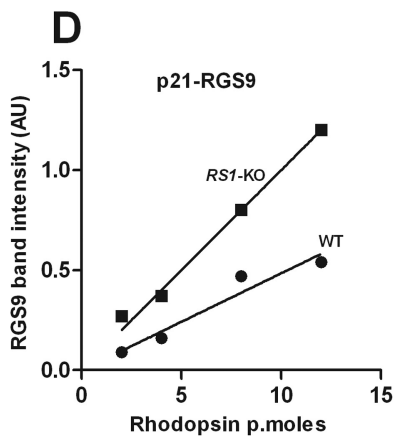

$\mathbf{F}$

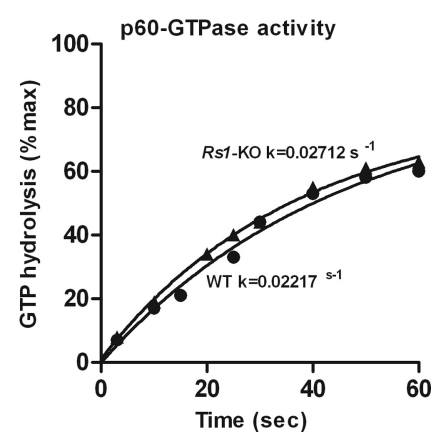

Figure 8. Quantitative immunoblot analyses (Odyssey imaging system; LI-COR) of key phototransduction protein subunits, transducin $\alpha\left(\mathrm{G} \alpha_{\mathrm{t} 1}\right), \mathrm{RGS9}, \mathrm{PDE} 6 \alpha$, andPDE6 $\gamma$, in dark-adapted outer segment extracts from P21 WT and Rs 1-K0 mice (A-D). Transducin $\alpha$ levels relative to rhodopsin were 15-30\% lower in Rs 1-K0 mice than in WT. RGS9, the GAP for G $\alpha_{\mathrm{t}}$, was 1.7- to 2.5-fold higher in Rs 1-K0 than in WT. Both PDE6 $\alpha$ and PDE6 $\gamma$ protein levels were marginally elevated in Rs1-K0 retinas. Replicate gels were run for each antibody tested. The time course of phosphate formation during hydrolysis of $\left[\gamma_{-}{ }^{32}\right.$ P]GTP by $G_{t}{ }^{*}$ in ROS of WT and Rs1-K0 mice at P21 $(\boldsymbol{E})$ and P60 $(\boldsymbol{F})$. In single-turnover GTPase activity measurements in isolated ROS, GTP hydrolysis by transducin was nearly twofold higher in Rs 1-K0 than in WT at P21, resulting in a shorter lifetime of activated transducin in Rs1-K0 ROS. The rates were not different at P60. The data were fitted to a single-phase exponential decay curve using GraphPad Prism (GraphPad Software).
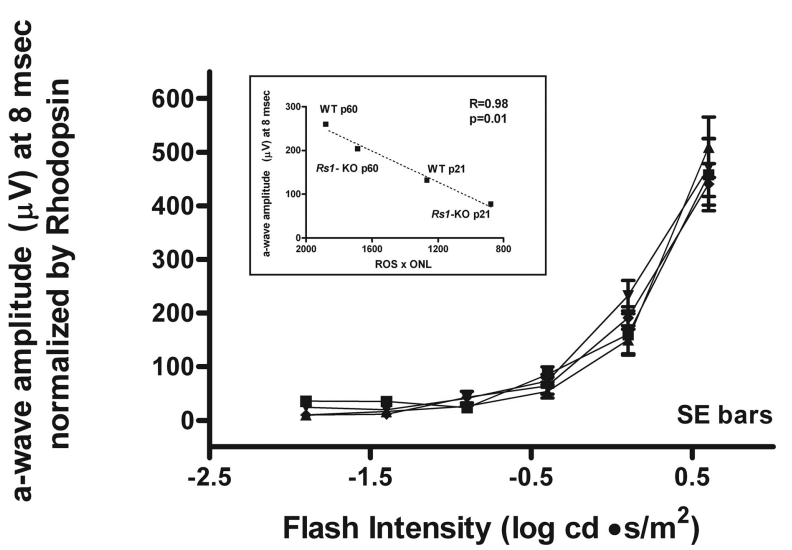

Figure 9. Intensity-response series of scotopic ERG a-wave amplitudes in P21 and P60 WT and Rs 1-K0 mice measured at $8 \mathrm{~ms}$ after the flash. Mean \pm SE amplitudes (microvolts) were normalized by the average dark-adapted whole retina rhodopsin content for each category of mice. The response curves for all groups of mice were essentially superimposed up to the maximum stimulus intensity of $+0.6 \log \mathrm{cd} \cdot \mathrm{s} / \mathrm{m}^{2}$. A linear correlation between the mean a-wave amplitude at $8 \mathrm{~ms}\left(+0.6 \log \mathrm{cd} \cdot \mathrm{s} / \mathrm{m}^{2}\right)$ and the product (ROS $\times$ ONL) calculated from the ONL widths and ROS lengths graphed in Figure 6 is displayed in the inset.

that arrestin movement is controlled by the availability of binding partners in the ROS (bleached rhodopsin) and the cell body (e.g., microtubules) (Slepak and Hurley, 2008). Our results appear not to be consistent with this hypothesis, because Rs1-KO photoreceptors had a much lower density of bleached rhodopsin in the ROS than WT under the same level of continuous illumination (Table 1), yet both had the same arrestin translocation threshold. Conversely, signaling via the phototransduction cascade as measured by the ERG a-wave whether normalized by rhodopsin or $(\mathrm{ROS} \times \mathrm{ONL})($ Fig. 9) was the same in Rs1-KO and WT retinas. The rate of bleached rhodopsin generation at steady state was similar in both genotypes as a result of differences in the rhodopsin regeneration rate constant, and this may be the critical factor determining the availability of binding sites for arrestin movement into the ROS, not the amount of bleached rhodopsin per se. When comparing mice that have similar rhodopsin kinetics, bleach level is probably an accurate way of evaluating the stoichiometry between photons and arrestin translocation.

Transcription factors, cell fate, and the Rs1-KO inner retinal phenotype

Our results demonstrate that loss of $R s 1$ gene function has a significant impact on the expression of photoreceptor transcription factor network genes, and morphological and functional defects in young (P21) Rs1-KO mice are consistent with changes in transduction proteins regulated by these genes. Although these and other transcription factors also help determine photoreceptor cell fate, commitment to cell fate occurs before the onset of Rs1 expression [P7 (Takada et al., 2004)] and does not appear to be altered in Rs1-KO mice. The reduction in Otx2 expression, a homeobox gene product essential for rod photoreceptor cell fate determination and also for morphological and electrophysiological maturation of bipolar cells (Koike et al., 2007), at P21 and P60 is consistent with long-term deficiency in 
OPL synaptic proteins (Takada et al., 2006), which is accompanied by a relatively larger decrease in the bipolar cell ERG b-wave than a-wave in the Rs1-KO mouse (Kjellstrom et al., 2007).

\section{References}

Alpern M, Krantz DH (1981) Visual pigment kinetics in abnormalities of the uvea-retinal epithelium interface in man. Invest Ophthalmol Vis Sci 20:183-203.

Baylor DA, Nunn BJ, Schnapf JL (1984) The photocurrent, noise and spectral sensitivity of rods of the monkey Macaca fascicularis. J Physiol 357:575-607.

Breton ME, Schueller AW, Lamb TD, Pugh EN Jr (1994) Analysis of ERG a-wave amplification and kinetics in terms of the G-protein cascade of phototransduction. Invest Ophthalmol Vis Sci 35:295-309.

Burns ME, Arshavsky VY (2005) Beyond counting photons: trials and trends in vertebrate visual transduction. Neuron 48:387-401.

Calvert PD, Govardovskii VI, Krasnoperova N, Anderson RE, Lem J, Makino CL (2001) Membrane protein diffusion sets the speed of rod phototransduction. Nature 411:90-94.

Calvert PD, Strissel KJ, Schiesser WE, Pugh EN Jr, Arshavsky VY (2006) Light-driven translocation of signaling proteins in vertebrate photoreceptors. Trends Cell Biol 16:560-568.

Cowan CW, Wensel TG, Arshavsky VY (2000) Enzymology of GTPase acceleration in phototransduction. Methods Enzymol 315:524-538.

Dowling JE (1963) Neural and photochemical mechanisms of visual adaptation in the rat. J Gen Physiol 46:1287-1301.

Elsaesser R, Kalra D, Li R, Montell C (2010) Light-induced translocation of Drosophila visual Arrestin2 depends on Rac2. Proc Natl Acad Sci U S A 107:4740-4745.

Fulton AB, Manning KA, Baker BN, Schukar SE, Bailey CJ (1982) Darkadapted sensitivity, rhodopsin content, and background adaptation in pcd/pcd mice. Invest Ophthalmol Vis Sci 22:386-393.

Fulton AB, Hansen RM, Findl O (1995) The development of the rod photoresponse from dark-adapted rats. Invest Ophthalmol Vis Sci 36:1038-1045.

Haruta M, Bush RA, Kjellstrom S, Vijayasarathy C, Zeng Y, Le YZ, Sieving PA (2009) Depleting Rac1 in mouse rod photoreceptors protects them from photo-oxidative stress without affecting their structure or function. Proc Natl Acad Sci U S A 106:9397-9402.

Hetling JR, Pepperberg DR (1999) Sensitivity and kinetics of mouse rod flash responses determined in vivo from paired-flash electroretinograms. J Physiol 516:593-609.

Hood DC, Birch DG (1993) Light adaptation of human rod receptors: the leading edge of the human a-wave and models of rod receptor activity. Vis Res 33:1605-1618.

Jeon CJ, Strettoi E, Masland RH (1998) The major cell populations of the mouse retina. J Neurosci 18:8936-8946.

Keller C, Grimm C, Wenzel A, Hafezi F, Rem é C (2001) Protective effect of halothane anesthesia on retinal light damage: inhibition of metabolic rhodopsin regeneration. Invest Ophthalmol Vis Sci 42:476-480.

Kerov V, Artemyev NO (2011) Diffusion and light-dependent compartmentalization of transducin. Mol Cell Neurosci 46:340-346.

Kerov V, Chen D, Moussaif M, Chen YJ, Chen CK, Artemyev NO (2005) Transducin activation state controls its light-dependent translocation in rod photoreceptors. J Biol Chem 280:41069-41076.

Kjellstrom S, Bush RA, Zeng Y, Takada Y, Sieving PA (2007) Retinoschisin gene therapy and natural history in the Rs $1 \mathrm{~h}-\mathrm{KO}$ mouse: long-term rescue from retinal degeneration. Invest Ophthalmol Vis Sci 48:3837-3845.

Koike C, Nishida A, Ueno S, Saito H, Sanuki R, Sato S, Furukawa A, Aizawa S, Matsuo I, Suzuki N, Kondo M, Furukawa T (2007) Functional roles of Otx2 transcription factor in postnatal mouse retinal development. Mol Cell Biol 27:8318-8329.

Lamb TD, Pugh EN Jr (2004) Dark adaptation and the retinoid cycle of vision. Prog Retin Eye Res 23:307-380.

LaVail MM (1973) Kinetics of rod outer segment renewal in the developing mouse retina. J Cell Biol 58:650-661.

Levine EM, Fuhrmann S, Reh TA (2000) Soluble factors and the development of rod photoreceptors. Cell Mol Life Sci 57:224-234.

Lobanova ES, Finkelstein S, Song H, Tsang SH, Chen CK, Sokolov M, Skiba NP, Arshavsky VY (2007) Transducin translocation in rods is triggered by saturation of the GTPase-activating complex. J Neurosci 27:1151-1160.

Machida S, Kondo M, Jamison JA, Khan NW, Kononen LT, Sugawara T, Bush RA, Sieving PA (2000) P23H rhodopsin transgenic rat: correlation of retinal function with histopathology. Invest Ophthalmol Vis Sci 41:3200-3209.

Manschot WA (1972) Pathology of hereditary juvenile retinoschisis. Arch Ophthalmol 88:131-138.

Mendez A, Lem J, Simon M, Chen J (2003) Light-dependent translocation of arrestin in the absence of rhodopsin phosphorylation and transducin signaling. J Neurosci 23:3124-3129.

Molday RS, Kellner U, Weber BH (2012) X-linked juvenile retinoschisis: clinical diagnosis, genetic analysis, and molecular mechanisms. Prog Retin Eye Res 31:195-212.

Nair KS, Hanson SM, Mendez A, Gurevich EV, Kennedy MJ, Shestopalov VI, Vishnivetskiy SA, Chen J, Hurley JB, Gurevich VV, Slepak VZ (2005) Light-dependent redistribution of arrestin in vertebrate rods is an energyindependent process governed by protein-protein interactions. Neuron 46:555-567.

Orisme W, Li J, Goldmann T, Bolch S, Wolfrum U, Smith WC (2010) Lightdependent translocation of arrestin in rod photoreceptors is signaled through a phospholipase C cascade and requires ATP. Cell Signal 22:447-456.

Penn JS, Anderson RE (1987) Effect of light history on rod outer-segment membrane composition in the rat. Exp Eye Res 44:767-778.

Penn JS, Williams TP (1986) Photostasis: regulation of daily photon-catch by rat retinas in response to various cyclic illuminances. Exp Eye Res 43:915-928.

Penn RD, Hagins WA (1972) Kinetics of the photocurrent of retinal rods. Biophys J 12:1073-1094.

Perlman I (1978) Kinetics of bleaching and regeneration of rhodopsin in abnormal (RCS) and normal albino rats in vivo. J Physiol 278:141-159.

Pugh EN, Falsini B, Lyubarsky AL (1998) The origin of the major rod- and cone-driven components of the rodent electroretinogram, and the effect of age and light-rearing history on the magnitude of these components. In: Photostasis and related topics (Williams TP, Thistle AB, eds), pp 93 128. New York: Plenum.

Ripps H, Mehaffey L 3rd, Siegel IM (1981) Rhodopsin kinetics in the cat retina. J Gen Physiol 77:317-334.

Robson JG, Frishman LJ (1998) Dissecting the dark-adapted electroretinogram. Doc Ophthalmol 95:187-215.

Satoh AK, Xia H, Yan L, Liu CH, Hardie RC, Ready DF (2010) Arrestin translocation is stoichiometric to rhodopsin isomerization and accelerated by phototransduction in Drosophila photoreceptors. Neuron 67:997-1008.

Sauer CG, Gehrig A, Warneke-Wittstock R, Marquardt A, Ewing CC, Gibson A, Lorenz B, Jurklies B, Weber BH (1997) Positional cloning of the gene associated with X-linked juvenile retinoschisis. Nat Genet $17: 164-170$.

Shichi H, Lewis MS, Irreverre F, Stone AL (1969) Biochemistry of visual pigments. I. Purification and properties of bovine rhodopsin. J Biol Chem 244:529-536.

Sieving PA, Chaudhry P, Kondo M, Provenzano M, Wu D, Carlson TJ, Bush RA, Thompson DA (2001) Inhibition of the visual cycle in vivo by 13-cis retinoic acid protects from light damage and provides a mechanism for night blindness in isotretinoin therapy. Proc Natl Acad Sci U S A 98:1835-1840.

Skeie JM, Tsang SH, Mahajan VB (2011) Evisceration of mouse vitreous and retina for proteomic analyses. J Vis Exp pii:2795.

Slepak VZ, Hurley JB (2008) Mechanism of light-induced translocation of arrestin and transducin in photoreceptors: interaction-restricted diffusion. IUBMB Life 60:2-9.

Sokolov M, Lyubarsky AL, Strissel KJ, Savchenko AB, Govardovskii VI, Pugh EN Jr, Arshavsky VY (2002) Massive light-driven translocation of transducin between the two major compartments of rod cells: a novel mechanism of light adaptation. Neuron 34:95-106.

Strissel KJ, Sokolov M, Trieu LH, Arshavsky VY (2006) Arrestin translocation is induced at a critical threshold of visual signaling and is superstoichiometric to bleached rhodopsin. J Neurosci 26:1146-1153.

Swaroop A, Kim D, Forrest D (2010) Transcriptional regulation of photo- 
receptor development and homeostasis in the mammalian retina. Nat Rev Neurosci 11:563-576.

Takada Y, Fariss RN, Tanikawa A, Zeng Y, Carper D, Bush R, Sieving PA (2004) A retinal neuronal developmental wave of retinoschisin expression begins in ganglion cells during layer formation. Invest Ophthalmol Vis Sci 45:3302-3312.

Takada Y, Fariss RN, Muller M, Bush RA, Rushing EJ, Sieving PA (2006) Retinoschisin expression and localization in rodent and human pineal and consequences of mouse RS1 gene knockout. Mol Vis 12:1108-1116.

Tansley K (1931) The regeneration of visual purple: its relation to dark adaptation and night blindness. J Physiol 71:442-458.

Tsang SH, Burns ME, Calvert PD, Gouras P, Baylor DA, Goff SP, Arshavsky VY (1998) Role for the target enzyme in deactivation of photoreceptor G protein in vivo. Science 282:117-121.
Wenzel A, Reme CE, Williams TP, Hafezi F, Grimm C (2001) The Rpe65 Leu450Met variation increases retinal resistance against light-induced degeneration by slowing rhodopsin regeneration. J Neurosci 21:53-58.

Winkler BS (1972) The electroretinogram of the isolated rat retina. Vis Res 12:1183-1198.

Zeng Y, Takada Y, Kjellstrom S, Hiriyanna K, Tanikawa A, Wawrousek E, Smaoui N, Caruso R, Bush RA, Sieving PA (2004) RS-1 gene delivery to an adult Rs1h knockout mouse model restores ERG b-wave with reversal of the electronegative waveform of X-linked retinoschisis. Invest Ophthalmol Vis Sci 45:3279-3285.

Zhang H, Huang W, Zhang H, Zhu X, Craft CM, Baehr W, Chen CK (2003) Light-dependent redistribution of visual arrestins and transducin subunits in mice with defective phototransduction. Mol Vis 9:231-237. 